\title{
Transcriptomic analysis reveals mechanism of light-sensitive albinism in tea plant Camellia sinensis 'Huangjinju'
}

\author{
Xinfeng Jiang ${ }^{1,2}$, Hua Zhao ${ }^{1}$, Fei Guo ${ }^{1}$, Xuping Shi ${ }^{2}$, Chuan Ye², Puxiang Yang ${ }^{2}$, Benying $\mathrm{Liu}^{3}$ and Dejiang $\mathrm{Ni}^{{ }^{*}}$
}

\begin{abstract}
Background: Camellia sinensis 'Huangjinju' is an albino tea variety developed recently in China. Young leaves of 'Huangjinju' demonstrate bright yellow when cultivated under natural sunlight, but regreens under reduced light intensity. To elucidate the physiological and molecular mechanisms of this light-sensitive albinism, we compared leaf pigmentation, metabolites, cellular ultrastructure and transcriptome between plants cultured under natural sunlight and shade.

Results: Shading treatment doubled the chlorophyll concentration and regreened albino leaves; carotenoid also increased by $30 \%$. Electron microscopy analyses showed that chloroplast not only increased in number but also in size with a complete set of components. In addition, regreened leaves also had a significantly higher concentration of polyphenols and catechins than albino leaves. At transcriptomic level, a total of 507 genes were differentially expressed in response to light condition changes. The most enriched pathways include light harvest protein complex, response to stimuli, oxidation-reduction process, generation of precursor metabolites and energy response.
\end{abstract}

Conclusion: The integrated strategy in this study allows a mechanistic understanding of leaf albinism in lightsensitive tea plants and suggested the regulation of gene networks involved in pigmentation and protein processing. Results from this study provide valuable information to this area and can benefit the domestication and artificial breeding to develop new albino tea varieties.

Keywords: Chloroplast, Leaf albinism, Leaf pigmentation, Metabolites, Photosynthesis, Tea

\section{Background}

Leaf color is a plastic phenotype and changes under different environmental conditions (e.g., light intensity, temperature and media composition). Leaf albinism is often considered deleterious and not favored in agriculture because it lacks essential pigmentation for normal functions such as photosynthesis [1, 2]; on the other hand, it produces specialties with some unique characteristics. In tea plant, for example, young albino leaves/

\footnotetext{
* Correspondence: nidj@mail.hzau.edu.cn

${ }^{1}$ College of Horticulture and Forestry Science, Huazhong Agricultural University, 1 Shizishan Street, Hongshan District, Wuhan 430070, Hubei, China Full list of author information is available at the end of the article
}

shoots are commercially grown because of its unique flavor compared to regular green tea [3]. There are two types of albinism in Camellia sinensis: temperaturesensitive (e.g., cultivars 'Anji Baicha', 'Baiye 1' and 'Xiaoxueya') and light-sensitive (e.g., cultivars 'Huangjinju', 'Huangjinya' and 'Baijiuan') [4]. As albino tea becomes internationally popular and the market continues to grow, understanding its molecular basis is in high demand and has a great economic value.

Light-sensitive albinism in tea plants involves modification in physiological and biochemical processes such as pigmentation, intracellular structure and metabolites [4]. The early development of leaves in albinistic plant 
typically experiences three stages: pre-albinistic stage, albinistic stage and regreening stage [5]. Most leaf albinism occurs in the albinistic stage, which lasts from several weeks to months. Reducing light intensity by artificial shielding often regreens leaves to the normal level. In the albinistic stage, leaf color varies from white to yellow depending on the level of deficiency in chlorophyll and carotenoids. Associated with the decrease in pigmentation is the often-observed abnormal development of chloroplasts and thylakoid membranes [6]. Albinism is also coupled with modified biochemical processes that contribute to changes in metabolites [7], which determines the flavor of brewed tea. Specifically, for example, high levels of amino acids bring an 'umami' taste; low levels of caffeine and catechins decrease the astringency and bitterness $[3,6,8]$.

In recent years, molecular techniques such as transcriptome sequencing provide opportunities to study the molecular mechanisms of tea albinism. Some photosynthesis-related genes and pathways have been shown to be involved in leaf albinism in tea plant, including pigmentation synthesis, protein processing, oxidation-reduction and flavonoid biosynthesis [9]. Pathways that contribute to essential metabolites are also shown to be involved, such as flavonoid biosynthesis and amino acid metabolism [4]. Although some genes and pathways are expected to be universally present in plant albinism, the ones that contribute to unique characteristics of each tea cultivar is of the greatest interest. The majority of existing literature has focused on several major cultivars such as C. sinensis 'Anji Baicha' [3, 5, 7, $10-12]$. Study on new tea varieties that are being actively developed is still limited.

'Huangjinju' is a light-sensitive albino cultivar of $C$. sinensis propagated from a natural variant in Jiangxi province, China [13]. Young leaves of 'Huangjinju' demonstrate yellow under natural sunlight, but gradually regreen as development progress. This study marks the first effort to explore the albinism mechanism in this cultivar. We applied integrated approaches to examine the response of pigmentation accumulation, metabolites, ultracellular structure and transcriptome to different light conditions by culturing plants under natural sunlight and shade. Results confirmed the role of some genes and pathways in photosynthesis and protein processing, but also identify additional pathways that are regulated to produce the unique characteristics in albino leaves.

\section{Results}

\section{Leaf pigmentation, chloroplast and metabolites} concentration

Young shoots of 'Huangjinju' emerged after trimming were yellow (Fig. 1). After 5 days of shading treatment, pale yellow leaves under shade gradually turned green. To quantify the "greenness" of leaves, we first measured Soil-Plant Analyses Development (SPAD) values in the field. By taking measurements on a total of 60 leaves for each treatment, SPAD values in shaded leaves were $36.8-52.3 \%$ higher than that in exposed leaves (Fig. 1g). The concentration of chlorophyll-a and chlorophyll-b in shaded leaves was twice as much as that in leaves under natural sunlight (Table 1), which agreed with the SPAD results. Similarly, carotenoids were also $30 \%$ higher in shaded leaves. We also observed that regreened leaves under shade had a significantly higher concentration of polyphenols and catechins than albino leaves under natural sunlight (Table 2).

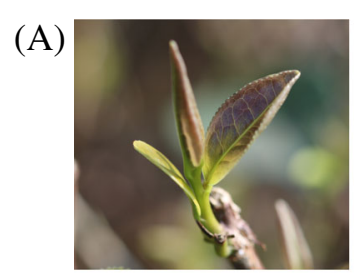

(D)

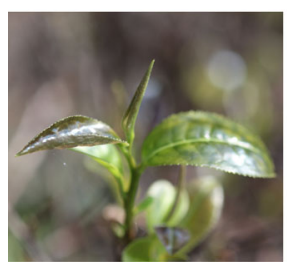

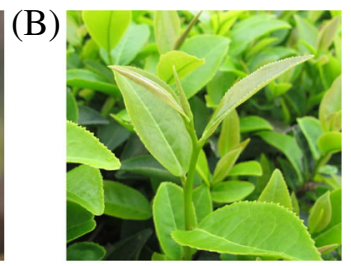

(E)

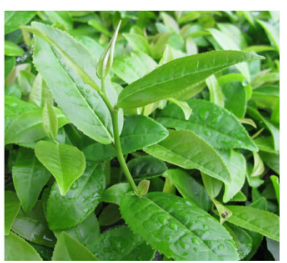

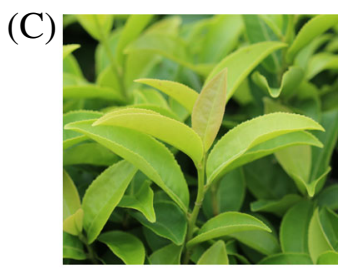

(F)

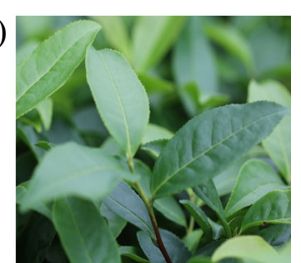

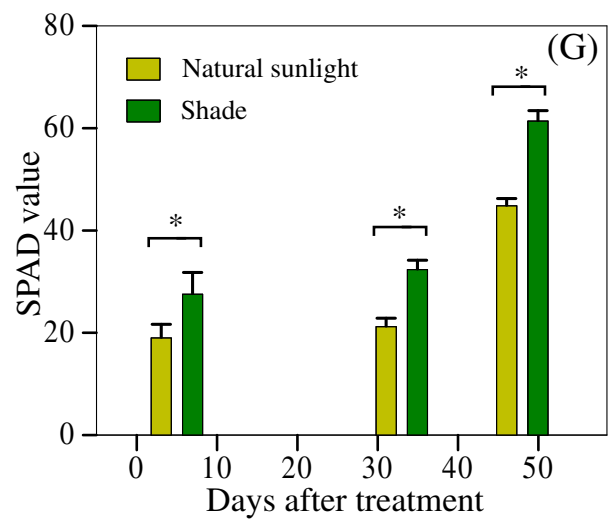

Fig. 1 Color differences in C. sinensis 'Huangjinju' cultured under natural sunlight versus under shade. a-c natural sunlight. $\mathbf{d}$-f shade treatment. a and $\mathbf{d}$ before treatment. $\mathbf{b}$ and $\mathbf{e} 20$ days after treatment. $\mathbf{c}$ and $\mathbf{f} 33$ days after treatment. $\mathbf{g}$ a bar plot of SPAD value for leaves under natural sunlight and shade. The asterisks indicate significant differences between treatments $(p<0.05)$. SPAD values were measured in the same day on day 5,33 and 48 after treatment 
Table 1 Pigment concentration of young shoots in C. sinensis 'Huangjinju' under natural sunlight (NS) and shade (S)

\begin{tabular}{llllll}
\hline & Sample mass $(\mathrm{g})$ & Chlorophyll-a $(\mathrm{mg} / \mathrm{g})$ & Chlorophyll-b $(\mathrm{mg} / \mathrm{g})$ & Total chlorophyll $(\mathrm{mg} / \mathrm{g})$ & Carotenoids $(\mathrm{mg} / \mathrm{g})$ \\
\hline NS-1 & 0.2032 & 0.40 & 0.08 & 0.5 & 320.3 \\
NS-2 & 0.2085 & 0.50 & 0.10 & 0.6 & 373.7 \\
S-1 & 0.2072 & 0.97 & 0.24 & 1.2 & 490.8 \\
S-2 & 0.208 & 0.83 & 0.22 & 1.1 & 441.8 \\
NS/S & 1.0 & 0.5 & 0.4 & 0.5 & 0.7 \\
S/NS & 1.0 & 2.0 & 2.6 & 2.1 & 1.3 \\
\hline
\end{tabular}

Pigmentation concentration was measured twice for both treatments. Each measurement used 100 randomly harvested leaves. The ratio of the average values between treatments is also calculated

\section{Cell ultrastructure}

Transmission electron microscopy (TEM) images showed abnormal cellular ultrastructure in leaves cultured under different light conditions. Chloroplast of leaves under natural sunlight had fewer starch granules (SG), osmiophilic granules (OG), and thylakoids (Th) stacking (Fig. 2a and c). In contrast, chloroplasts were fully developed in shaded leaf and no abnormity was found in thylakoid membranes and granular stacking (Fig. 2b and d).

\section{Differential gene expression}

A total of 304.8 million raw reads were obtained from the sequencer. After applying quality filtering processes, 301.8 million clean reads were retained for downstream analysis. An average of $85.2 \%$ of the total reads was uniquely aligned to the reference genome. A total of 41,444 unique transcripts were identified. Compared to plants under natural sunlight, plants

Table 2 Concentrations of tea metabolites in C. sinensis 'Huangjinju' under natural sunlight and shade

\begin{tabular}{lll}
\hline & Natural sunlight & Shade \\
\hline $\mathrm{N}$ & 8 & 8 \\
Amino acid & $2.09 \pm 0.05$ & $2.13 \pm 0.05$ \\
Caffeine & $3.23 \pm 0.07$ & $3.41 \pm 0.14$ \\
Polyphenol & $19.8 \pm 1.6^{\mathrm{a}}$ & $24.9 \pm 1.3^{\mathrm{b}}$ \\
Total Catechin & $15.1 \pm 1.5^{\mathrm{a}}$ & $18.2 \pm 1.1^{\mathrm{b}}$ \\
Gallate & $0.030 \pm 0.007$ & $0.026 \pm 0.005$ \\
Epigallocatechin & $0.22 \pm 0.01^{\mathrm{a}}$ & $0.28 \pm 0.02^{\mathrm{b}}$ \\
Catechin & $0.08 \pm 0.01^{\mathrm{a}}$ & $0.12 \pm 0.01^{\mathrm{b}}$ \\
Epicatechin & $0.47 \pm 0.07$ & $0.53 \pm 0.03$ \\
Epigallocatechin gallate & $12.2 \pm 1.7$ & $14.3 \pm 1.0$ \\
Gallocatechin gallate & $0.18 \pm 0.05$ & $0.17 \pm 0.04$ \\
Epicatechin gallate & $1.78 \pm 0.4^{\mathrm{a}}$ & $2.51 \pm 0.4^{\mathrm{b}}$ \\
Catechin gallate & $0.13 \pm 0.01^{\mathrm{a}}$ & $0.20 \pm 0.03^{\mathrm{b}}$ \\
\hline All &
\end{tabular}

All numbers are relative weight (\%). Data are presented as mean \pm s.e.m. Significant differences $(p<0.05)$ between treatments are denoted with different lower-case letters under shade treatment significantly regulated 507 genes (Fig. 3), which includes 198 up-regulated genes and 309 down-regulated transcripts (Details of the differentially expressed gene (DEGs) are given in supplementary Table S1). The most significantly upregulated gene is WRKY3O (WRKY DNA-binding protein 30) with a 9.4-fold increase, while the most significantly down-regulated DEG is CYP (cytochrome P450) with 111-fold decrease. The gene that held the greatest absolute difference is $L H C B$ (light-harvesting complex II chlorophyll a-b binding protein) followed by LIP (light-inducible protein).

Gene ontology (GO) analysis suggested that DEGs were mostly involved in three categories: "response to stimulus", "oxidation-reduction process" and "generation of precursor metabolites and energy response" (Fig. 4 and Fig. S1). The child terms of "response to stimulus" include functions related to "response to heat", "response to organic substance" and "response to hormone". Some DEGs in "generation of precursor metabolites and energy response" are involved in photosynthesis processes. Pathways of processing denatured proteins and misfolded proteins became less active as suggested by the downregulation of heat shock protein genes. Functional categories of DEGs from GO analyses are listed in supplementary Table S2.

Mapping to Kyoto Encyclopedia of Genes and Genomes (KEGG) ortholog database revealed three significantly enriched pathways: "Photosynthesis - antenna proteins" (ath00196) (Fig. 5a), "Protein processing in endoplasmic reticulum" (ath04141) (Fig. 5b) and "Brassinosteroid biosynthesis" (ath00905). Some DEGs in "Protein processing in endoplasmic reticulum" pathway was also involved in endocytosis, plant-pathogen interaction, spliceosome and protein export processes. DEGs were also discovered in other pathways such as "Photosynthesis", "flavonoid biosynthesis pathway", "Biosynthesis of amino acid pathway" and "Carotenoid biosynthesis", which are known to be involved in response to light condition changes. Functional categories of DEGs KEGG analyses are listed in supplementary Table S3. 


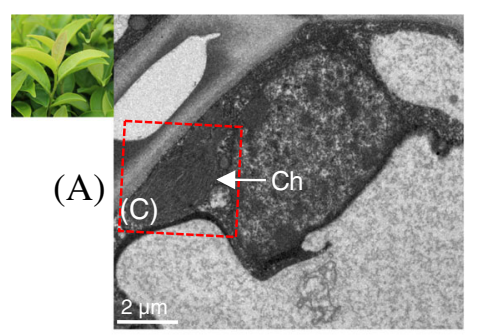

(B)
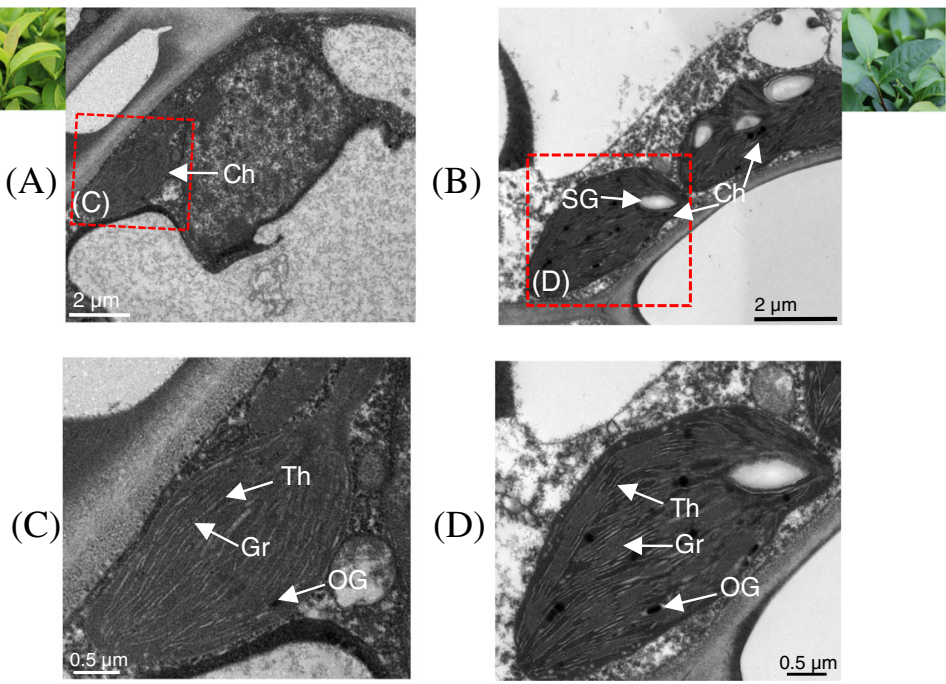

(D)

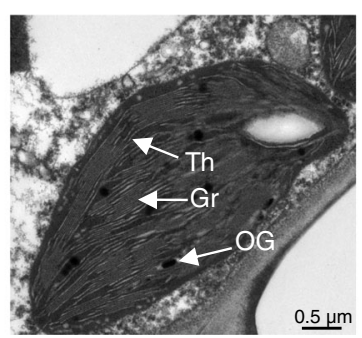

Fig. 2 Cellular ultrastructure of young shoots in C. sinensis 'Huangjinju' under direct sunlight and shade. a and c leaves under natural sunlight. b and $\mathbf{d}$ leaves under shade. Ch: chloroplast; SG: starch granule; OG: osmiophilic granule; Th: thylakoid; Gr: grana

\section{Discussion}

Light intensity is among the most critical environmental factors affecting plant physiology and biochemistry. In most situations, albinism is a hereditary condition caused by mutations that may have occurred in the nuclear or chloroplast genomes. The molecular mechanism likely not only involves a group of genes but also some degree of interaction among them. Here we show that albino tea plants significantly regulated the expression of numerous structural and regulatory genes in response to light. Reducing light intensity causes the pale yellow 'Huangjinju' leaves to regreen with increased chlorophyll and carotenoid deposition. Regreened leaves also had significantly higher polyphenols and catechins content than pale leaves. Meanwhile, the gene expression profile significantly differed between treatments in pathways such as photosynthesis, protein folding, amino acid metabolism, cellular structure and oxidation.

Leaf color variation is determined by pigmentations, including chlorophyll and carotenoid. Albino

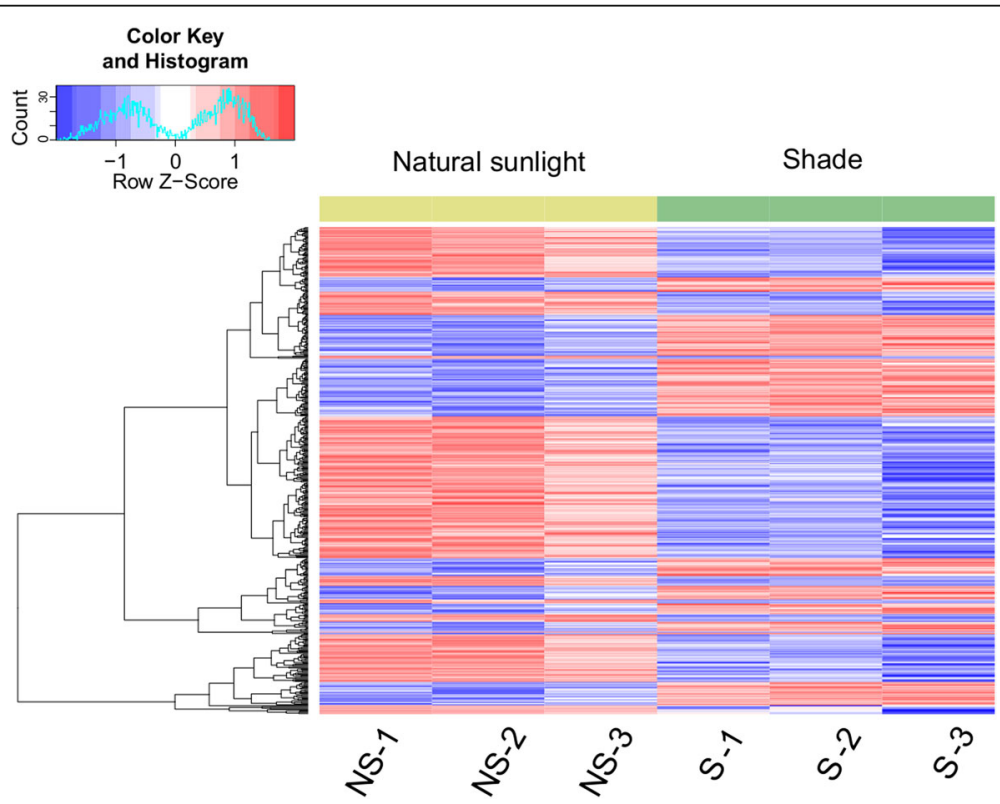

Fig. 3 Heatmap of differentially expressed genes in plants under shade (S) versus under natural sunlight (NS) 


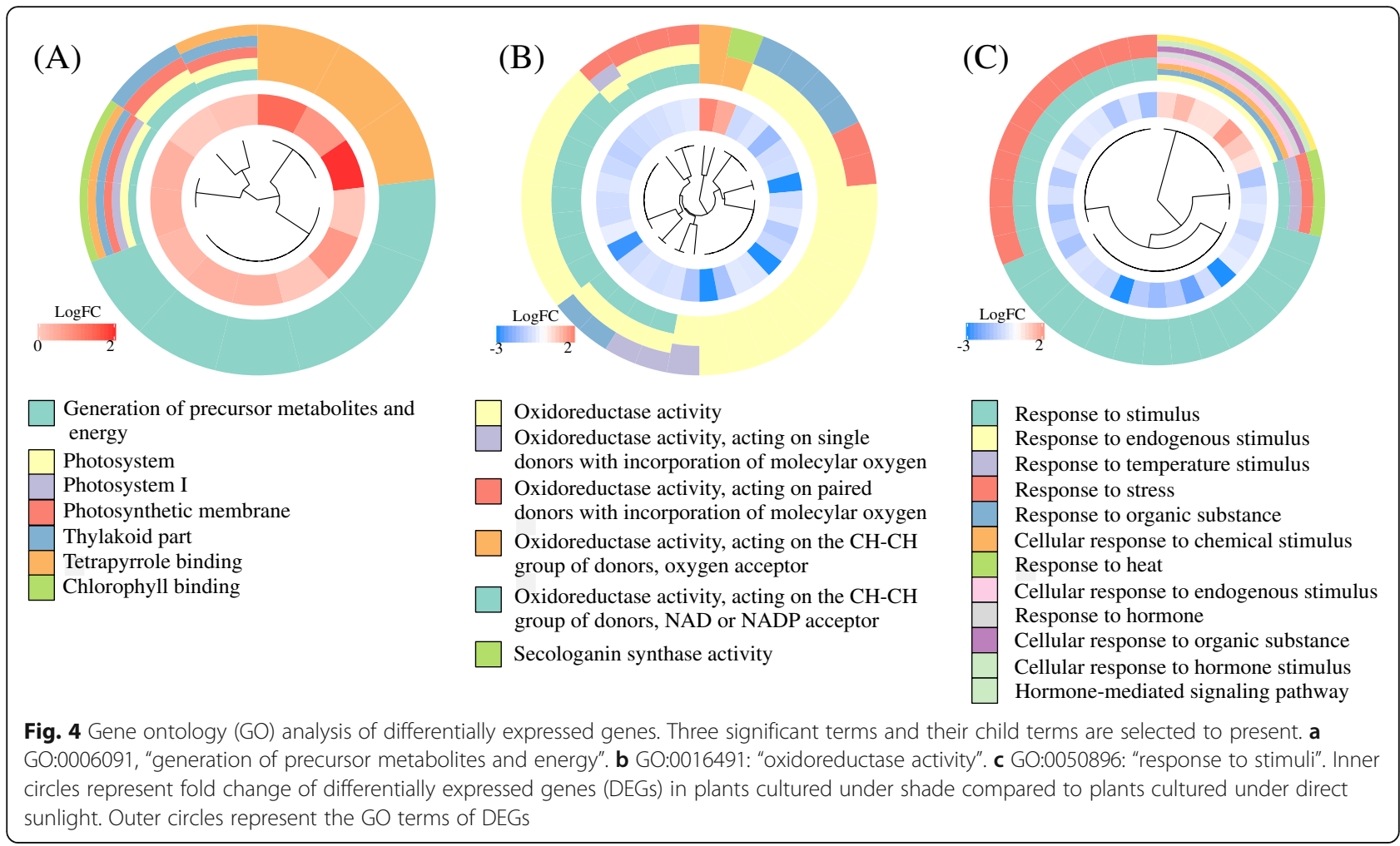

'Huangjinju' leaves under natural sunlight are low in chlorophyll, therefore, lack the green pigmentation. Leaves also demonstrated some yellow color, despite that carotenoid was decreased by $20 \%$. Lack of chlorophyll accumulation is a result of the maldevelopment of chloroplast [14]. Aberrant chloroplast has been found to be universal in both light-sensitive and temperaturesensitive albino cultivars. Direct exposure to natural sunlight induces hypoplasia of chloroplasts in young shoots by suppressing the development of grana stacking and thylakoids.

\section{Photosynthesis pathway}

The light-harvesting complex is an aggregate of proteins and photosensitive pigments that absorb light and transfer energy. The contents of pigment-protein complexes gradually increase during the regreening stages in albino plants [10]. We observed significant upregulation of transcripts from chlorophyll $a-b$ binding protein genes in regreened leaves under the shade, suggesting the recovery of photosynthesis activities. Antenna complex also contains carotenoids, lutein, violaxanthin and b-carotene. Beta-carotene isomerase gene was downregulated, which reduced the digestion of $\beta$-carotene and helped to accumulate $\beta$-carotene. We also observed the downregulation of 9-cis-epoxycarotenoid dioxygenase that catalyzes
Violaxanthin / Neoxanthin to Xanthoxin. Xanthoxin is a precursor of abscisic acid that is important for plants to deal with environmental stressors. This result is suggesting that the stress level of plants under reduced light intensity has decreased. It is a similar result as that in C. sinensis 'Huangjinya', where carotenoid biosynthesis-related genes were induced by shading treatment [15]. We also observed the upregulation of light-responsive gene PORA (protochlorophyllide reductase, chloroplastic), which is involved in chlorophyll biosynthesis by catalyzing the formation of chlorophyllide from protochlorophyllide during biosyntheses of chlorophylls and bacteriochlorophylls.

\section{Management of proteins}

External stresses disturb the process of protein synthesis and denaturation. Cells deal with denatured proteins via either rescue or degradation. Cells produce heat shock proteins, which act as molecular chaperones to rescue and stabilize misfolded proteins pathway [16]. Therefore, heat shock protein is sometimes considered as an indicator of stress level. Here we found that heat shock protein DEGs were all downregulated under shade, suggesting that plants became less stressed under shade, which supports the conclusion from the photosynthesis pathway analysis. For proteins that are damaged and cannot be rescued, cells engage the process of protein degradation 


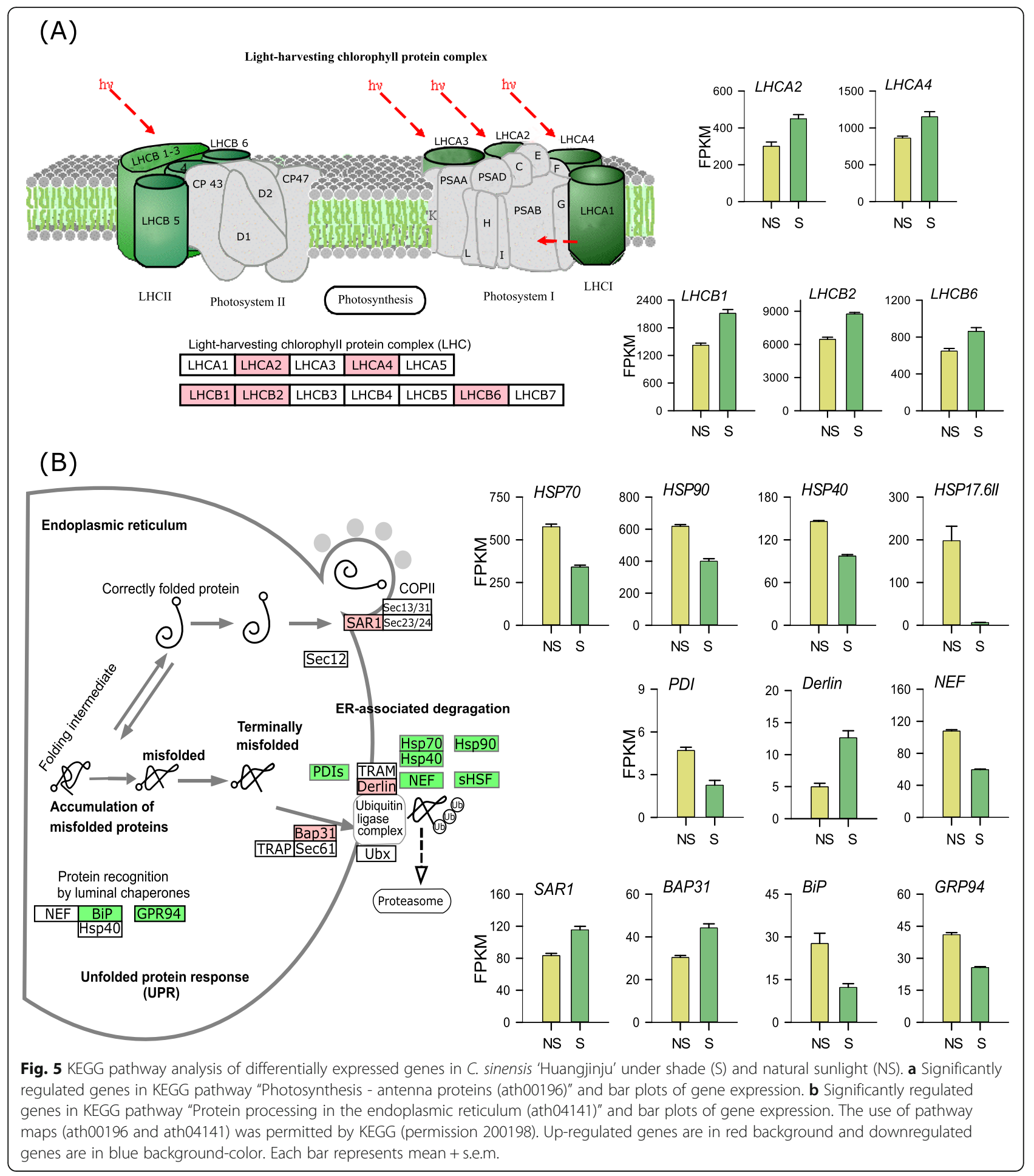

through the ubiquitin/proteasome pathway [17]. Similar to previous studies $[18,19]$, three of the four ubiquitination-related DEGs were downregulated, suggesting a decreased need for disposal of denatured proteins under reduced light conditions. Gene expression patterns of protein rescue and degradation indicate that protein synthesis is more disrupted in albino leaves, which may have caused the accumulation of total amino acids during the albinism process [8]. Indeed, we have identified that DEGs are involved in the metabolism of cysteine, methionine, lysine, glycine, serine, threonine and tyrosine. 


\section{Oxidation stress reduction}

Reactive oxygen species (ROS) is a group of molecules produced from metabolic processes in chloroplast, mitochondria and peroxisome. ROS include superoxide anion, hydrogen peroxide, and hydroxyl radicals, which are all highly reactive molecules and affect normal cellular functions by interacting with nucleic acids, proteins and lipids [20]. ROS is normally controlled within a safe range through detoxification processes, but can be trigger by environmental stresses, e.g., strong light condition $[21,22]$. On the one hand, ROS causes molecular damages and affects cellular processes [20,21]; on the other hand, the effect of ROS might be a strategy for cells to survive stressful conditions by temporarily turning off some processes [22]. For example, in Chinese poplar Populus simonii, ROS production in the early chilling response resulting in inhibition of photosynthesis to produce a survival advantage [23]. Cytochrome P450 catalyzes most of the steps in the detoxification process of secondary metabolisms in plants [24]. In this study, we identified nine transcripts from Cytochrome $\mathrm{P} 450$ were significantly more expressed in plants under shade than that in plants exposed to natural sunlight. Similar results were also discovered for other enzymes involved in the oxidation-reduction process, including flavonoid 3 '-hydroxylase 2, flavonoid 3'-hydroxylase 3 , leucoanthocyanidin dioxygenase, carbamoyl-phosphate synthetase 2 , aspartate transcarbamylase, and dihydroorotase. Therefore, the albino leaves might be caused by the accumulation of ROS, which is a response of plants to deal with strong light conditions.

\section{Transcription factors}

Transcription factors (TFs) regulate the complex transcription network and therefore are involved in a series of mechanisms to cope with abiotic stresses. We observed significant downregulation of TFs after shading, suggesting the reduction of environmental stress. The differentially expressed TFs in this study belong to gene families of $M Y B, b H L H$, Ethylene Response Factors (ERFs), NAC, GRAS, WRKY, etc. Regulation of these gene families has been previously shown responsive to abiotic stressors [25], such as temperature [26-28], chemicals [29,30], salinity [31], light condition [9, 32]. It is not surprising that NAC and WRKY were both significantly regulated as they are two of the largest TF families in plants. In C. sinensis, NAC and WRKY have been shown to be responsive to all the aforementioned stressors [9, 28, 29, 31]. In C. sinensis 'Shuchazao', the expression of $M Y B$ family genes has been shown to be positively associated with the UV level [32]. Therefore, the upregulation of $M Y B$ family genes in the natural sunlight exposed group in this study may be a result of strong UV radiation. In addition, MYB TFs are involved in flavonoid biosynthesis [33], which has been shown to be significantly different between treatment groups in this study, e.g., catechins and polyphenols. However, the direct association warrants further investigation. Previous studies showed that $b H L H$ TFs likely function cooperatively with $M Y B s$ to deal with environmental stressors and affect flavonoid biosynthesis [34]. The $E R F s$ are involved in the ethylene signaling pathway that regulates many processes in development stress responses. We observed three downregulated genes (CRF4, ERF4 and RAP2-4) and one up-regulated gene (WIN1).

\section{Conclusions}

Taking together, tea is the most consumed nonalcoholic beverages around the world and new varieties are still continually being developed. Knowledge on the molecular basis of albinism provides valuable information that is commercially relevant. This paper provided some mechanistic understanding of albinism at multiple biological levels from transcriptome, molecular to cellular, which all suggest albinism in young leaves might be a result of stress responses. Further research in this area should lead to the accumulation of adequate information to allow a comprehensive understanding of how leaf color is affected by different environmental factors.

\section{Methods}

\section{Plant and treatments}

Twenty-year-old tea plants of $C$. sinensis cultivar 'Huanginju' were grown at Eco-tea Garden of Jiangxi Sericulture and Tea Research Institute, Jiangxi province, China $\left(28^{\circ} 22^{\prime} 14.5^{\prime \prime} \mathrm{N} \quad 116^{\circ} 00^{\prime} 05.8^{\prime \prime} \mathrm{E}\right)$. Elevation of experiment field is $36 \mathrm{~m}$. Abiotic and biotic conditions, except the light condition, were maintained the same throughout this study. On May 10, 2018, tea plants were trimmed and divided into two groups: one group was under natural sunlight, the other group was covered with black polyethylene shading net (width, $15.0 \mathrm{~m}$; length $6.0 \mathrm{~m}$; height: $1.8 \mathrm{~m}$ ) that blocks out $70 \%$ of sunlight. On June 10, 2018 when plants reached one bud and two leaves stage, the difference in leave color was visually apparent. Leaf samples were randomly sampled and snap-frozen in liquid nitrogen before stored at $-80^{\circ} \mathrm{C}$.

\section{Determination of pigmentation content}

Pigmentation content in leaves was quantified using two methods: Soil-Plant Analyses Development (SPAD) and high-performance liquid chromatography (HPLC). The SPAD method is a quick measurement of relative chlorophyll amount in fresh leaf samples using a handheld device SPAD-502PLUS (Spectrum Technologies, Konica Minolta, Japan). This SPAD device takes readings directly from fresh leaves and therefore, does not require 
additional sample processing. The SPAD measurements were conducted on six biological replicates for each treatment. In each replicate, a total of ten leaves were measured and the average value was logger as a SPAD value. The HPLC analysis of pigments including chlorophyll a, chlorophyll b, and b-carotene was previously described in Li et al., 2015 [6]. Briefly, 100 randomly harvested fresh young shoots were ground, and $0.2 \mathrm{~g}$ of the ground product was extracted with $10 \mathrm{ml}$ acetone and $0.1 \mathrm{~g}$ polyvinylpolypyrrolidone. The mixture was centrifuged at $12,000 \mathrm{rpm}$ for $15 \mathrm{~min}\left(4^{\circ} \mathrm{C}\right)$. The supernatant was analyzed on the LC-20AT HPLC System (Shimadzu, Kyoto, Japan) with a TC-C18 column (Agilent Technologies Inc., Santa Clara, CA, USA). The injection volume was $20 \mu \mathrm{l}$. The column was eluted at $35^{\circ} \mathrm{C}$ with a linear gradient increasing from 80 to $100 \%$ mobile phase B (acetonitrile/methanol/chloroform:15/4/ $1, \mathrm{v} / \mathrm{v} / \mathrm{v}$ ) over $20 \mathrm{~min}$ at a flow rate of $1 \mathrm{ml} \mathrm{min}^{-1}$. After an additional $15 \mathrm{~min}$ at $100 \%$ mobile phase B, the gradient was linearly decreased from 100 to $80 \%$ over $5 \mathrm{~min}$, and then $80 \%$ mobile phase B for an additional $5 \mathrm{~min}$. The eluent was detected at the wavelength of $440 \mathrm{~nm}$. An external standard was used as an authentic reference to quantify detected pigments.

\section{Determination of free amino acids content}

Free amino acid content was determined according to the national standard (GB/T 8314-2013). Briefly, fresh shoots (one bud and two leave stage) were fixed by steaming for three min. Fixed leaves were then dried at $80^{\circ} \mathrm{C}$ for $3 \mathrm{~h}$. Dried leaves were ground to powder and passed through a $0.45 \mathrm{~mm}$-mesh sieve. Then, $3.0 \mathrm{~g}$ of the fine power were placed in $450 \mathrm{ml}$ of boiling water for $45 \mathrm{~min}$ to make the extract solution. The extract solution was then filtered through a Double-Ring No. 102 filter paper (Xinhua Paper Industry Co. Ltd., Hangzhou, China), and the volume was increased to $500 \mathrm{ml}$ by adding distilled water. Next, $1 \mathrm{ml}$ of the solution was transferred to a $25 \mathrm{ml}$ flask, followed by the addition of $0.5 \mathrm{ml}$ of buffer ( $\mathrm{pH} 8.0$ ) containing 63 $\mathrm{mM} \mathrm{Na}_{2} \mathrm{HPO}_{4}$ and $3 \mathrm{mM} \mathrm{KH}_{2} \mathrm{PO}_{4}, 0.5 \mathrm{ml}$ of a $2 \%$ ninhydrin solution $\left(2 \mathrm{~g}\right.$ ninhydrin and $80 \mathrm{mg} \mathrm{SnCl}_{2} \cdot 2 \mathrm{H}_{2} \mathrm{O}$ dissolved in $100 \mathrm{ml}$ of water). The flask was incubated at boiling temperature for $15 \mathrm{~min}$. The volume was then increased to $25 \mathrm{ml}$ with $\mathrm{H}_{2} \mathrm{O}$. The absorbance $(570 \mathrm{~nm})$ of the mixture was measured with a UV Spectrophotometer U-2800 (Hitachi High-Technologies Corporation, Tokyo, Japan). Total free amino acid content was calculated from a standard curve generated with varying concentrations of glutamine.

\section{Determination of total polyphenols, catechins and caffeine content}

The concentration of total polyphenols was determined by spectrophotometry, as described in the national standard of China (GB/T 8313-2018) with minor modifications. Briefly, 100 randomly harvested fresh young shoots (one-bud and two-leaf stage) were ground, and $0.2 \mathrm{~g}$ of the ground product was mixed with $5.0 \mathrm{~mL} 70 \%$ ethanol. The mixture was incubated at $70{ }^{\circ} \mathrm{C}$ for $10 \mathrm{~min}$ and stirred every $5 \mathrm{~min}$. After the mixture was cooled to room temperature, it was centrifuged at $3500 \mathrm{rpm}$ for $10 \mathrm{~min}$. The supernatant was separated and added to a $10 \mathrm{~mL}$ volumetric flask. The sediment was remixed with $5.0 \mathrm{~mL} \mathrm{70 \%} \mathrm{ethanol} \mathrm{and} \mathrm{repeated} \mathrm{the} \mathrm{procedure.} \mathrm{Super-}$ natants from each step were collected in a volumetric flask and adjusted to $10 \mathrm{~mL}$ with deionized water $\left(4{ }^{\circ} \mathrm{C}\right)$ to form the extract solution. A volume of $1 \mathrm{~mL}$ of extract solution was placed in a measuring flask and adjusted to $100 \mathrm{~mL}$ with deionized water to form the test solution. To measure total polyphenols, test solution (1 $\mathrm{mL}$ ) was then mixed with $10 \%$ Folin Ciocalteu reagent $(5 \mathrm{~mL})$ in a test tube for $5 \mathrm{~min}$. Next, $4 \mathrm{~mL}$ of $\mathrm{Na}_{2} \mathrm{CO}_{3}$ solution $\left(75 \mathrm{~g} \mathrm{~L}^{-1}\right)$ was added to the test tube, and the mixture was stirred for one $h$ at room temperature. The absorbance of test solution was measured with a UV Spectrophotometer U-2800 (Hitachi High-Technologies Corporation, Tokyo, Japan) at $765 \mathrm{~nm}$. Gallic acid at different concentrations $\left(10,20,30,40\right.$, and $50 \mu \mathrm{g} \mathrm{mL}^{-1}$ ) was used as a reference, and the polyphenol results were presented as gallic acid equivalent concentrations. To measure catechins and caffeine, test solution $(2 \mathrm{~mL})$ was first mixed with $25 \mathrm{~mL}$ stabilizing solution $(25 \mathrm{ml}$ EDTA-2Na at $10 \mathrm{mg} \mathrm{mL}^{-1} ; 50 \mathrm{~mL}$ chromatographically pure Acetonitrile; $25 \mathrm{~mL}$ ascorbic acid at $10 \mathrm{mg} \mathrm{mL}^{-1}$ : water, $400 \mathrm{ml}$ ) and then filtered through a $0.45 \mu \mathrm{m}$ membrane (Millipore, Billerica, MA, USA). An aliquot of $10 \mu \mathrm{L}$ filtrate was measured using an LC-10ATVP HPLC system (Shimadzu, Tokyo, Japan). The HPLC conditions were as follows: inject volume, $20 \mu \mathrm{l}$; $\mathrm{C} 18$ column, $5 \mu \mathrm{m}$, $250 \mathrm{~mm} \times 4.6 \mathrm{~mm}$ (Agilent Technologies Inc., Santa Clara, CA, USA); $35^{\circ} \mathrm{C}$; gradient elution: started with phase A (100\%) for $10 \mathrm{~min}$, in $15 \mathrm{~min}$ phase A decreased to $68 \%$ phase $A$ and $32 \%$ phase $B$ and held for $10 \mathrm{~min}$, reaching $100 \%$ phase $\mathrm{A}$; flow rate: $1 \mathrm{ml} \mathrm{min}^{-1}$; mobile phase A (2 ml EDTA-2Na at $10 \mathrm{mg} \mathrm{mL}^{-1}$; $90 \mathrm{~mL}$ chromatographically pure Acetonitrile; $25 \mathrm{~mL}$ Acetic acid at $20 \mathrm{mg} \mathrm{mL}^{-1}$ : water, $\left.888 \mathrm{ml}\right)$, mobile phase $\mathrm{B}(2 \mathrm{ml}$ EDTA-2Na at $10 \mathrm{mg} \mathrm{mL}^{-1} ; 800 \mathrm{~mL}$ chromatographically pure Acetonitrile; $20 \mathrm{~mL}$ Acetic acid at $10 \mathrm{mg} \mathrm{mL}^{-1}$ : water, $178 \mathrm{ml}$ ); detection wavelength: $278 \mathrm{~nm}$.

\section{Chloroplast ultrastructure analysis}

The chloroplast ultrastructure was analyzed using transmission electron microscopy (TEM) facilities at the Institute of Virology, Chinese Academy of Science, Jiangxi Province, China, following the protocol previously described in Wang et al., 2014 [35]. Briefly, fresh leaves were firstly cut into $1 \mathrm{~cm} \times 2 \mathrm{~cm}$ pieces. Pieces without 
leaf veins were chosen and fixed in glutaraldehyde solution $(2.5 \%)$ at $4{ }^{\circ} \mathrm{C}$ overnight. Samples were then washed with phosphate buffer $(0.1 \mathrm{M}, \mathrm{pH} 7.0)$ three times $(20$ min each). After washing, samples were fixed again in $\mathrm{O}_{\mathrm{S}} \mathrm{O}_{4}$ solution $\left(1 \%, 4{ }^{\circ} \mathrm{C}\right)$ for $2-3 \mathrm{~h}$ and washed three times with phosphate buffer $(0.1 \mathrm{M}, \mathrm{pH} 7.0)$. After fixation steps, samples were sequentially subjected to a graded ethanol series (50, 70, 80, 85, 90, 95 and 100\%) for dehydration. Each dehydration step lasted $15 \mathrm{~min}$, followed by soaking in 100\% ethanol for 20 min. Dehydrated samples were sequentially drenched in the mixture of acetone: epoxy resin (2:1), acetone: epoxy resin (1:1) and epoxy resin. Drenched samples were embedded in pure epoxy resin at $60^{\circ} \mathrm{C}$ for $48 \mathrm{~h}$. After embedding, 60-100 nm thick sections were cut with an EM UC6 microtome (Leica, Vienna, Austria) and stained with saturated uranyl acetate in 50\% ethanol for $15 \mathrm{~min}$ and $0.2 \%(\mathrm{w} / \mathrm{v})$ lead citrate for $15 \mathrm{~min}$. Images were taken under a Tecnai $G^{2} 20$ TWIN transmission electron microscope (FEI, Oregon, United States).

\section{RNA-Seq and bioinformatics}

Total RNA was extracted using a TRlzol reagent (Invi$\operatorname{trogen}^{\text {tw }}$ Life Technologies, CA, USA) according to the manufacturer's manual. The RNA concentration was quantified using Qubit $^{\circ}$ RNA Assay Kit in Qubit $^{\circ} 2.0$ Flurometer (Life Technologies, CA, USA) while RNA integrity was tested with RNA Nano 6000 Assay Kit of the 2100 Bioanalyzer Instrument (Agilent Technologies, CA, USA). RNA-Seq libraries were prepared using NEBNext ${ }^{\circ}$ Ultra $^{\text {tm }}$ RNA Library Prep Kit (NEB, USA) according to the manufacturer's manual. Libraries were pair-end sequenced on an Illumina Hiseq 2500 platform (Novogene, Beijing, China). Raw reads were quality controlled by filtering adapter sequences, reads containing more than $10 \%$ ploy- $\mathrm{N}$ and low-quality sequences using customized Perl script. Clean reads were aligned to tea plant Camellia sinensis reference genome [36] (http://tpia.teaplant. org/) using Hisat2 v2.0.4 [37]. HTSeq v0.9.1 was used to count the reads numbers mapped to each gene.

\section{Differential gene expression}

Gene counts were normalized to FPKM (Fragments Per Kilobase of transcript sequence per Millions base pairs sequenced) based on the length of the gene and number of reads mapped to this gene [38]. Differentially expressed gene (DEGs) analysis of two light conditions (three biological replicates per condition) was performed using the R package DESeq (1.18.0) [39]. DESeq determines differential gene expression using statistical methods modelled with the negative binomial distribution. A Benjamin -Hochberg's approach was used to adjust the $p$-values with cutoff at 0.05 [40].

\section{Enrichment analysis of DEGs}

Functional category and pathways of DEGs were annotated by searching against public databases to form a better understanding of the molecular mechanism. Gene Ontology (GO) enrichment analysis of DEGs was implemented by the GOseq $R$ package [41], in which gene length bias was corrected. The significance level of enrichment analysis was tested using Fisher's Exact test. GO terms with over-represent p-value less than 0.05 were considered significantly enriched by DEGs. Kyoto Encyclopedia of Genes and Genome (KEGG) pathway database is a collection of pathway maps representing current knowledge on molecular interaction and reaction networks [42]. Transcripts were aligned against the KEGG database for ortholog annotation. Statistical enrichment of pathways was tested in KOBAS software [43].

\section{Statistical analysis}

Significant differences between treatments were determined using a Student's two-tailed t-test with SPSS 20.0 software (IBM Corporation, Chicago, IL, USA) and values of $p<0.05$ were considered statistically significant.

\section{Supplementary information}

Supplementary information accompanies this paper at https://doi.org/10. 1186/s12870-020-02425-0.

Additional file 1: Table S1. Summary of differentially expressed genes Additional file 2: Table S2. Summary of gene ontology (GO) analyses. Additional file 3: Table S3. Summary of Kyoto Encyclopedia of Genes and Genomes (KEGG) pathway enrichment analyses.

Additional file 4: Fig. S1. Gene ontology enrichment of differentially expressed genes identified in leaves under direct sunlight versus under shade. Only up to 10 terms are selected to present. Horizontal redline represents the threshold of significance after false discovery rate correction.

\section{Abbreviations}

DEG: Differentially expressed gene; GO: Gene ontology; Gr: grana; HPLC: high performance liquid chromatography; S: natural sunlight; KEGG: Kyoto Encyclopedia of Genes and Genomes; OG: osmiophilic granules; ROS: Reactive oxygen species; SPAD: Soil-Plant Analyses Development; SC: shade control; SG: starch granules; TEM: transmission electron microscopy; Th: thylakoids

\section{Acknowledgements \\ The authors thank Pei Zhang and An-Na Du from The Core Facility and Tech- nical Support, Wuhan Institute of Virology, for their help in producing TEM} micrographs.

\section{Authors' contributions}

$\mathrm{DN}, \mathrm{XJ}$ and $\mathrm{BL}$ conceived and designed the experiments with input from PY. $\mathrm{HZ}$ and $\mathrm{FG}$ provided help in RNA sequencing. XS and CY provided resources for TMS analysis. XJ conducted experiments, analyzed data and drafted the manuscript. All authors have read and approved the final manuscript.

\section{Funding}

This work was supported by research funds from the Key Laboratory of Tea Quality and Safety Control in Jiangxi Province (grant number

20192BCD40007) to XJ for performing experiments, data analysis, writing and 
publication. The sequencing of RNA was funded by The Open Fund of Yunnan Provincial Key Laboratory of Tea Science program (2017YNCX001) to $\mathrm{BL}$.

\section{Availability of data and materials}

Raw sequencing data files are available in the NCBI SRA database with project accession NO. PRJNA589096.

\section{Ethics approval and consent to participate}

Not applicable.

\section{Consent for publication}

Not applicable.

\section{Competing interests}

The authors declare that they have no competing interest.

\section{Author details}

${ }^{1}$ College of Horticulture and Forestry Science, Huazhong Agricultural University, 1 Shizishan Street, Hongshan District, Wuhan 430070, Hubei, China. ${ }^{2}$ Jiangxi Sericulture and Tea Research Institute, Nanchang 330202, Jiangxi, China. ${ }^{3}$ Yunnan Provincial Key Laboratory of Tea Science, Jinghong 666100, Yunnan, China.

Received: 26 December 2019 Accepted: 30 April 2020

Published online: 14 May 2020

\section{References}

1. Caredda S, Clément C. Androgenesis and albinism in Poaceae: influence of genotype and carbohydrates. In: Anther and Pollen. Berlin: Springer Berlin Heidelberg; 1999. p. 211-28. https://doi.org/10.1007/978-3-642-59985-9_20.

2. Kumari M, Clarke HJ, Small I, Siddique KHM. Albinism in plants: a majo bottleneck in wide hybridization, androgenesis and doubled haploid culture. CRC Crit Rev Plant Sci. 2009;28:393-409. https://doi.org/10.1080/ 07352680903133252

3. Feng L, Gao MJ, Hou RY, Hu XY, Zhang L, Wan XC, et al. Determination of quality constituents in the young leaves of albino tea cultivars. Food Chem. 2014;155:98-104. https://doi.org/10.1016/j.foodchem.2014.01.044.

4. Shin Y-H, Yang R, Shi Y-L, Li X-M, Fu Q-Y, Lu J-L, et al. Light-sensitive albino tea plants and their characterization. HortScience. 2018:53:144-7.

5. Li Q, Huang J, Liu S, Li J, Yang X, Liu Y, et al. Proteomic analysis of young leaves at three developmental stages in an albino tea cultivar. Proteome Sci. 2011;9:1-12

6. Li N, Yang Y, Ye J, Lu J, Zheng X, Liang Y. Effects of sunlight on gene expression and chemical composition of light-sensitive albino tea plant. Plant Growth Regul. 2016;78:253-62.

7. Li CF, Ma JQ, Huang DJ, Ma CL, Jin JQ, Yao MZ, et al. Comprehensive dissection of metabolic changes in albino and green tea cultivars. J Agric Food Chem. 2018:66:2040-8.

8. Wang KR, Li NN, Du YY, Liang YR. Effect of sunlight shielding on leaf structure and amino acids concentration of light sensitive albino tea plant. African J Biotechnol. 2013;12:5535.

9. Wu Q, Chen Z, Sun W, Deng T, Chen M. De novo Sequencing of the Leaf Transcriptome Reveals Complex Light-Responsive Regulatory Networks in Camellia sinensis cv. Baijiguan. Front Plant Sci. 2016;7:1-15.

10. Xu Y-X, Chen W, Ma C-L, Shen S-Y, Zhou Y-Y, Zhou L-Q, et al. Proteome and acetyl-proteome profiling of Camellia sinensis cv. 'Anji Baicha' during periodic albinism reveals alterations in photosynthetic and secondary metabolite biosynthetic pathways. Front. Plant Sci. 2017;8. https://doi.org/10. 3389/fpls.2017.02104.

11. Li CF, Yao MZ, Ma CL, Ma JQ, Jin JQ, Chen L. Differential metabolic profiles during the albescent stages of "Anji Baicha" (Camellia sinensis). PLoS One. 2015;10:1-18.

12. $M a C L$, Chen L, Wang $X C$, Jin JQ, Ma JQ, Yao MZ, et al. Differential expression analysis of different albescent stages of "Anji Baicha" (Camellia sinensis (L.) O. Kuntze) using CDNA microarray. Sci Hortic (Amsterdam). 2012; 148:246-54. https://doi.org/10.1016/j.scienta.2012.09.033.

13. Jiang X, Li C, Cai X, Xie X, Shi X, Li Y, et al. Effects of shading treatment on growing and quality of "Huangjinju"(Camellia sinensis). J Te a Commun. 2019;46:424-8 (in Chinese with English abstract).
14. Fambrini M, Castagna A, Vecchia FD, Degl'Innocenti E, Ranieri A, Vernieri $P$, et al. Characterization of a pigment-deficient mutant of sunflower (Helianthus annuus L.) with abnormal chloroplast biogenesis, reduced PS II activity and low endogenous level of abscisic acid. Plant Sci. 2004;167:79_ 89. https://doi.org/10.1016/j.plantsci.2004.03.002.

15. Song L, Ma Q, Zou Z, Sun K, Yao Y, Tao J, et al. Molecular link between leaf coloration and gene expression of flavonoid and carotenoid biosynthesis in Camellia sinensis cultivar 'Huangjinya.' Front Plant Sci. 2017;8:1-12.

16. Schöffl F, Prändl $R$, Reindl A. Regulation of the heat-shock response. Plant Physiol. 1998;117:1135-41. https://doi.org/10.1104/pp.117.4.1135.

17. Glickman $\mathrm{MH}$, Ciechanover $\mathrm{A}$. The ubiquitin-proteasome proteolytic pathway: destruction for the sake of construction. Physiol Rev. 2002;82:373428. https://doi.org/10.1152/physrev.00027.2001.

18. Yuan L. Xiong L gui, Deng T ting, Wu Y, Li J, Liu S qian, et al. comparative profiling of gene expression in Camellia sinensis L. cultivar AnJiBaiCha leaves during periodic albinism. Gene. 2015;561:23-9. https://doi.org/10.1016/j. gene.2015.01.007.

19. Ma Q, Li H, Zou Z, Arkorful E, Lv Q, Zhou Q, et al. Transcriptomic analyses identify albino-associated genes of a novel albino tea germplasm 'Huabai 1. Hortic Res 2018;5. doi:https://doi.org/10.1038/s41438-018-0053-y.

20. Tripathy BC, Oelmüller R. Reactive oxygen species generation and signaling in plants. Plant Signal Behav. 2012;7:1621-33. https://doi.org/10.4161/psb. 22455.

21. Gechev TS, Van Breusegem F, Stone JM, Denev I, Laloi C. Reactive oxygen species as signals that modulate plant stress responses and programmed cell death. BioEssays. 2006;28:1091-101. https://doi.org/10.1002/bies.20493.

22. Bolwell GP, Wojtaszek P. Mechanisms for the generation of reactive oxygen species in plant defence - a broad perspective. Physiol Mol Plant Pathol. 1997;51:347-66. https://doi.org/10.1006/pmpp.1997.0129.

23. Song $Y$, Chen $Q, C i D$, Zhang D. Transcriptome profiling reveals differential transcript abundance in response to chilling stress in Populus simonii. Plant Cell Rep. 2013;32:1407-25. https://doi.org/10.1007/s00299-013-1454-x.

24. Ayabe S, Akashi T. Cytochrome P450s in flavonoid metabolism. Phytochem Rev. 2006:5:271-82. https://doi.org/10.1007/s11101-006-9007-3.

25. Lindemose S, O'Shea C, Jensen M, Skriver K. Structure, function and networks of transcription factors involved in abiotic stress responses. Int J Mol Sci. 2013;14:5842-78. https://doi.org/10.3390/ijms14035842.

26. Wu ZJ, Li XH, Liu ZW, Li H, Wang YX, Zhuang J. Transcriptome-based discovery of AP2/ERF transcription factors related to temperature stress in tea plant (Camellia sinensis). Funct Integr Genomics. 2015:15:741-52.

27. Zheng C, Zhao L, Wang Y, Shen J, Zhang Y, Jia S, et al. Integrated RNA-Seq and sRNA-Seq analysis identifies chilling and freezing responsive key molecular players and pathways in tea plant (Camellia sinensis). PLoS One. 2015;10:1-28

28. Wang XC, Zhao QY, Ma CL, Zhang ZH, Cao HL, Kong YM, et al. Global transcriptome profiles of Camellia sinensis during cold acclimation. BMC Genomics. 2013;14:1. https://doi.org/10.1186/1471-2164-14-415.

29. Cao D, Liu Y, Ma L, Jin X, Guo G, Tan R, et al. Transcriptome analysis of differentially expressed genes involved in selenium accumulation in tea plant (Camellia sinensis). PLoS One. 2018;13:e0197506.

30. Li Y, Huang J, Song X, Zhang Z, Jiang Y, Zhu Y, et al. An RNA-Seq transcriptome analysis revealing novel insights into aluminum tolerance and accumulation in tea plant. Planta. 2017:246:91-103.

31. Wan S, Wang W, Zhou T, Zhang Y, Chen J, Xiao B, et al. Transcriptomic analysis reveals the molecular mechanisms of Camellia sinensis in response to salt stress. Plant Growth Regul. 2018;84:481-92. https://doi.org/10.1007/ s10725-017-0354-4.

32. Liu L, Li Y, She G, Zhang X, Jordan B, Chen Q, et al. Metabolite profiling and transcriptomic analyses reveal an essential role of UVR8-mediated signal transduction pathway in regulating flavonoid biosynthesis in tea plants (Camellia sinensis) in response to shading. BMC Plant Biol. 2018;18:233. https://doi.org/10.1186/s12870-018-1440-0.

33. Wang W-L, Wang Y-X, Li H, Liu Z-W, Cui X, Zhuang J. Two MYB transcription factors (CSMYB2 and CsMYB26) are involved in flavonoid biosynthesis in tea plant [Camellia sinensis (L.) O. Kuntze]. BMC Plant Biol. 2018;18:288. https:// doi.org/10.1186/s12870-018-1502-3.

34. Baudry A, Caboche M, Lepiniec L. TT8 controls its own expression in a feedback regulation involving TTG1 and homologous MYB and bHLH factors, allowing a strong and cell-specific accumulation of flavonoids in Arabidopsis thaliana. Plant J. 2006:46:768-79. https://doi.org/10.1111/j.1365313X.2006.02733.x 
35. Wang L, Yue C, Cao H, Zhou Y, Zeng J, Yang Y, et al. Biochemical and transcriptome analyses of a novel chlorophyll-deficient chlorina tea plant cultivar. BMC Plant Biol. 2014;14:352.

36. Wei C, Yang H, Wang S, Zhao J, Liu C, Gao L, et al. Draft genome sequence of Camellia sinensis var. sinensis provides insights into the evolution of the tea genome and tea quality. Proc Natl Acad Sci. 2018;115:E4151-8. https:// doi.org/10.1073/pnas.1719622115.

37. Kim D, Langmead B, Salzberg SL. HISAT: a fast spliced aligner with low memory requirements. Nat Methods. 2015;12:357-60. https://doi.org/10. 1038/nmeth.3317.

38. Trapnell C, Williams BA, Pertea G, Mortazavi A, Kwan G, van Baren MJ, et al. Transcript assembly and quantification by RNA-Seq reveals unannotated transcripts and isoform switching during cell differentiation. Nat Biotechnol. 2010;28:511-5. https://doi.org/10.1038/nbt.1621.

39. Anders $\mathrm{S}$, Huber $\mathrm{W}$. Differential expression analysis for sequence count data. Genome Biol. 2010;11:R106. https://doi.org/10.1186/gb-2010-11-10-r106.

40. Benjamini Y, Hochberg Y. Controlling the false discovery rate: a practical and powerful approach to multiple testing. J R Stat Soc Ser B. 1995;57:289300. https://doi.org/10.2307/2346101.

41. Young MD, Wakefield MJ, Smyth GK, Oshlack A. Gene ontology analysis for RNA-seq: accounting for selection bias. Genome Biol. 2010;11:R14. https:// doi.org/10.1186/gb-2010-11-2-r14.

42. Kanehisa M, Sato Y, Furumichi M, Morishima K, Tanabe M. New approach for understanding genome variations in KEGG. Nucleic Acids Res. 2019;47: D590-5.

43. Xie C, Mao X, Huang J, Ding Y, Wu J, Dong S, et al. KOBAS 2.0: a web server for annotation and identification of enriched pathways and diseases. Nucleic Acids Res. 2011;39(suppl_2):W316-22. https://doi.org/10.1093/nar/ gkr483.

\section{Publisher's Note}

Springer Nature remains neutral with regard to jurisdictional claims in published maps and institutional affiliations.

Ready to submit your research? Choose BMC and benefit from:

- fast, convenient online submission

- thorough peer review by experienced researchers in your field

- rapid publication on acceptance

- support for research data, including large and complex data types

- gold Open Access which fosters wider collaboration and increased citations

- maximum visibility for your research: over $100 \mathrm{M}$ website views per year

At $\mathrm{BMC}$, research is always in progress.

Learn more biomedcentral.com/submissions 